\title{
LA CULTURA DEL VOTO EN LA PROVINCIA DE CARTAGENA 1810-1840*
}

\author{
Edwin Monsalvo Mendoza
}

\begin{abstract}
Resumen
Este trabajo realiza una aproximación a las prácticas del voto en el espacio provincial cartagenero. Centra su atención en los mecanismos a través de los cuales los dirigentes cartageneros buscaron obtener los sufragios necesarios para impulsar sus "candidaturas". El estudio de las prácticas de consecución de sufragios permite comprender la idea que esta sociedad tenía de la individualidad, la libertad, la igualdad y la ciudadanía.
\end{abstract}

Palabras claves: Voto, derecho al sufragio, pueblo, ciudadanía.

\section{Abstract}

This paper is a practical approach to the vote in provincial Cartagenero space. It focuses on the mechanisms through which leaders sought to obtain the votes Cartagena necessary to drive their "nominations". The study of practices achieving votes for understanding the structure of society participating in epileptic events, since we unveiled the idea that these were about concepts such as individuality, freedom, equality and citizenship.

Key words: Vote, right to vote, people, citizenship.

El rechazo al gobierno de José Bonaparte y la constitución de Juntas de Gobierno en España tras la crisis de 1808, tuvo su correlato en América también en la organización de Juntas, pero sobre todo en las discusiones de nuevos principios de legitimidad política: soberanía popular, igualdad civil y representación política'. En teoría, el problema de la legitimidad fue rápidamente resuelto (ésta recaía inmediatamente en los pueblos); en la práctica, fue mucho más complejo hacer efectivos los principios previamente referidos en pos del logro de estabilidad.

En tiempos de autonomías provinciales y federación, el principio de soberanía popular legitimaba el ejercicio del poder. Este se traducía en el mecanismo electoral, a través del cual los gobiernos provinciales "organizaron [...] un eficaz control sobre sus nuevos espacios políticos" (Annino, 1995, p.

\footnotetext{
"Artículo tipo 2: de reflexión según clasificación de Colciencias. Hace parte de la investigación "De vecinos a ciudadanos. Elecciones, movilización y cultura política en la Nueva Granada 1821-1843" financiado por la Universidad de Caldas, código 0175212.

** Doctor en Historia de América Hispánica, Universidad de San Pablo. Director del Departamento de Historia y Geografía de la Universidad de Caldas. Email: edwinmonsalvo @ gmail.com.

${ }^{1}$ Acerca del concepto de soberanía popular ver Chiaramonte (1997); especialmente, de la segunda parte del libro, el capítulo primero. Este trabajo subrayó el papel de los primeros procesos electorales como el marco en el que se desarrollaron, paralelamente, dos concepciones de soberanía, una entendida como popular, ciudadana e individual y otra como pueblos, es decir, ciudades. Acerca del concepto de igualdad, también había una polisemia: Mientras que unos pocos hacían referencia a la igualdad política, otros señalaban la socio-racial y otros la de la naturaleza. Ver Andrews Reid (2007. p. 149).
} 
13). Así las elecciones funcionaban como el único acto capaz de conferir legitimidad al poder político, sin embargo este mecanismo enfrentaba dos serios inconvenientes, el primero era la definición del pueblo soberano ¿Quiénes podían ser ciudadanos?, es decir ¿quiénes podían votar? La solución a este problema no fue nada fácil porque coexistieron distintas y múltiples definiciones de la palabra pueblo y porque el moderno concepto de ciudadanía estuvo mezclado con el tradicional término de vecindad ${ }^{2}$ (Chiaramonte, 1997 y 2004), de tal manera que pese a los esfuerzos de los legisladores por definir los criterios de la ciudadanía, ésta se vio sometida a los vaivenes de los conflictos políticos.

En segundo lugar, y una vez definido el objeto de los derechos políticos, es decir, el pueblo, que estaría encarnado en la figura del ciudadano, faltaba por enfrentar el problema de la mecánica electoral, lo que significaba que había que crear una estrategia que permitiera que la sociedad, a través de su sufragio, se representara. Esto planteó la cuestión de cómo debían votar las personas. Si las elecciones se convirtieron en el mecanismo privilegiado de representación, ¿a quién se representaba, quiénes y cómo? estas preguntas remiten al carácter del voto, es decir a la manera cómo la sociedad concibió el acto del sufragio y la importancia que le otorgó a este.

Teniendo en cuenta el anterior esquema, el voto adquiere una importancia sin precedentes ya que es a través de él $-\mathrm{y}$ de todas las prácticas que giran alrededor de los "momentos del voto"- que la sociedad ejercía sus derechos políticos. (Gueniffey, 2001) Aunque como señala Raffaele Romanelli, el voto no fue nunca un mecanismo tendencialmente automático a través del cual la sociedad se representaba políticamente -y que la corrupción podía distorsionar, más bien el acto comicial era "un proceso en el cual los grupos sociales y de poder experimentaron estrategias de control y de cooptación de electores, en las cuales entran en juego viejos y nuevos equilibrios de elites", un mundo de intercambios articulados que permiten "pensar las elecciones como una estructura política intermedia entre el estado y la sociedad". (Annino y Romanelli, 1988) En este sentido el estudio de las prácticas electorales

\footnotetext{
${ }^{2}$ Tal polisemia llevó a que se terminara por entender por pueblo soberano, no la idea abstracta que la representación moderna recogía en el término "ciudadanía", sino por el contrario se entendió el pueblo concreto de la sociedad tradicional, representada en castas, grupos y clases. Así en la documentación del periodo se utiliza indistintamente la palabra pueblo para referirse a las provincias del Estado como el plural "pueblos" para indicar un conglomerado de territorios y corporaciones. Acerca de la noción de pueblos ver Quijada Mónica (1994); Chiaramonte (1997); Chiaramonte (2004, pp. 218); Guerra (1999, pp. 33-61); Guerra F. X. (1993, pp. 39-67). Acerca de la vecindad es importante señalar que en el manejo que las autoridades dieron a este concepto con fines electorales está la clave para comprender la relación entre ciudadanía y vecindad en América Latina, como acertadamente lo han comprobado los trabajos de Antonio Annino (1992, p. 121-158). Marta Irurozqui estudió los comicios de 1814, en los que se eligieron diputados a las Cortes Generales de la Nación española- Potosí y La Paz, develando los significados y valores que asumió la categoría ciudadana para los contemporáneos. A partir de esta documentación ella demuestra que ciudadano y vecino eran conceptos complementarios, que significaban un status social (de reconocimiento) y jurídico (de aceptación). (Irurozqui, 2005, p. 614, pp. 451-484); también: Herzog (2000, pp. 123-131). En ambos casos se pone énfasis en el carácter de categoría social de la condición de vecindad. La renovación de los estudios electorales también ha permitido avanzar en los estudios sobre ciudadanía, llegando a comprenderla desde una perspectiva bastante amplia, en la que el derecho de voto no la define automáticamente. Sin embargo la existencia de la ciudadanía pasa por la presencia de un sistema electoral.
} 
conducentes a la consecución de sufragios permiten comprender la estructura de la sociedad que participó en los comicios.

Aunque los comicios siempre habían sido un tema presente en la historiografía política, durante las últimas dos décadas del siglo pasado, y como resultado de la renovación en la historia política y social, la temática electoral ha cobrado una vigencia sin precedentes. Las nuevas investigaciones han insistido en la importancia de las elecciones para la formación del gobierno representativo ${ }^{3}$, la alternancia en el poder y la participación de amplios sectores sociales en los comicios ${ }^{4}$. Así mismo el conocimiento de los procesos de democratización en Europa y Norteamérica ${ }^{5}$, ha permitido superar la tendencia a resaltar la corrupción y el fraude como rasgos de la experiencia "típicamente americana" y subrayar el papel que el sistema electoral de la constitución de Cádiz jugó en el desarrollo de la democracia en el siglo XIX hispanoamericano.

El objeto de este trabajo es realizar una aproximación a las prácticas del voto en el espacio provincial cartagenero ${ }^{6}$, centrando nuestra atención en los mecanismos a través de los cuales los dirigentes buscaron obtener los sufragios necesarios para impulsar sus "candidaturas". El trabajo está dividido en cuatro partes, en primer lugar se plantea el problema de la definición del pueblo soberano, haciendo un acercamiento al debate en torno a la inclusión y exclusión de una parte de la población de los derechos políticos y la ciudadanía durante la primera década de vida republicana en la provincia de Cartagena. En el segundo y tercer acápites, se describen las discusiones en torno a los derechos de sufragio de la tropa y la injerencia de los curas de las parroquias en las elecciones. Ambos actores generaron serias dudas a los coetáneos sobre la libertad e individualidad del sufragio y representaron a su vez dos formas de captación del voto. En la última parte del texto se describen otras prácticas a las que frecuentemente recurrieron los dirigentes cartageneros en búsqueda de sufragios para las elecciones parroquiales: los convites, el ofrecimiento de aguardiente, las fiestas con comida y los numerarios, fueron estrategias aprovechadas por los intermediarios políticos para cautivar sufragios que les permitieran negociar con los notables locales y a su vez

\footnotetext{
${ }^{3}$ En el trabajo se hará referencia al concepto de sistema representativo, por este entendemos un sistema de gobierno en el que los ciudadanos confían a través de las elecciones, a unos representantes el ejercicio del poder y la redacción de las leyes. Este sistema representativo es distinto y opuesto a la democracia tal como era entendida por la sociedad del siglo XIX. También es parecido a lo que hoy denominamos con el término democracia representativa, en oposición a democracia directa. Ver Manin (1998).

${ }^{4}$ Aunque la bibliografía es abundante, solo mencionaremos algunos trabajos: Posada Carbó (1996); Valenzuela (1985); Sabato y Palti (1990); Sabato (1992; 2003); McEvoy (1997); Peloso (1996); Murilo de Carvalho (1995); Graham (1990); Carmagnani y Hernández-Chávez (1999); Escalante (1992); Hernández-Chávez (1993); Botana (1977); Malamud (1997).

${ }_{5}^{5}$ Especial contribución han tenido los trabajos de O’Gorman (1989; 1992, pp. 79- 115); Rosanvallon (1992); Gueniffey (1993); Romanelli (1998).

${ }^{6}$ Las prácticas electorales pueden coincidir o no con los principios. Pero, a su vez, esta relación de correspondencia, supone adjudicarle un determinado sentido a ambos términos. El sentido que les adjudiquemos como historiadores puede ser diferente al que les adjudicaron los coetáneos. Es así que hasta hace poco tiempo, se suponía que este cambio en el modo de fundamentar la legitimidad del poder político sobre bases liberales, tenía su correlato en un cambio en las prácticas. Sin embargo, este esquema que hoy rechaza la historiografía por demasiado mecanicista, no tenía en cuenta las complejidades de la vida social. Este desfase es el que lleva a preguntarse por el sentido que asumían las prácticas políticas como las de votar en el siglo pasado.
} 
fueron usados por estos últimos para obtener los votos necesarios para un triunfo eleccionario.

\section{¿Quiénes podían votar?}

La constitución de Cartagena, publicada sólo tres meses después de la gaditana, estableció el derecho al voto a los negros libres ${ }^{7}$, ello implicaba que en esta provincia se impusiera el derecho de sufragio de una forma más amplia que en los territorios donde se juró la constitución de Cádiz. Sin embargo, esto no debe leerse como parte de un "espíritu democrático" de los legisladores de Cartagena, en realidad esta fue resultado de la presión social que ejercieron las castas de color, no sólo en términos demográficos sino en el ejercicio de la acción política. (Múnera, 1998) y (Sourdis, 1988). Tal aseveración puede ser demostrada con la siguiente instrucción expedida por la Junta de la Provincia de Cartagena en 1810, quien en su propósito de reorganizarse y de convertirse en un órgano representativo de los distintos intereses provinciales, implantó un reglamento en el que estableció la forma como debían llevarse a cabo las elecciones para el nombramiento de los diputados elegidos por los pueblos de la provincia. En este documento se instituyó que a partir de principios de 1811 la junta estaría conformada por doce miembros elegidos por el pueblo de la siguiente forma: "El juez local de cada Parroquia citará el día anterior al señalado para las elecciones, á todos los vecinos del distrito de la Parroquia, blancos, indios, mestizos, mulatos, zambos y negros con tal que sean padres de familia, ó que tengan casa poblada, y que vivan de su trabajo, (pues solos los vagos, los que hayan cometido un delito, que induzca infamia los que estén en actual servidumbre asalariados, y los esclavos serán excluidos de ellas) para que concurran a la Iglesia" ${ }^{8}$ donde se celebraría a la hora de la Misa

\footnotetext{
7 “Constitución política del Estado de Cartagena de Indias expedida el 14 de Junio de 1812”, en El pensamiento constitucional hispanoamericano hasta 1830, Caracas, Biblioteca de la Academia Nacional de la Historia, 1961, tomo IV.

${ }^{8}$ Fondo José Manuel Restrepo, Archivo del CEDHIR, Universidad Industrial de Santander. Rollo No 5 Vol. 9-14 f. 20. diciembre 11 de 1810. "Instrucción que deberá observarse en las elecciones Parroquiales, en las de Partido, y en las Capitulares para el nombramiento de Diputados en la Suprema Junta de la Provincia de Cartagena". Cursivas nuestras. Mientras se realizaban las elecciones la junta estaría compuesta por seis miembros elegidos por Cartagena, tres por los pueblos y los tres restantes por la misma junta. El propósito de reorganizar la junta era darle un carácter ejecutivo. Así "formada la junta al principio de diputados que nombró el pueblo de aquella capital y que se habían asociado al ilustre ayuntamiento, a cuyo celo y actividad se debieron aquellas útiles reformas, era preciso que dicho cuerpo regenerador volviese a las funciones de su ministerio, y que para hacer una representación legitima se nombrasen diputados por toda la provincia, en razón de su población como efectivamente se determino, previniéndose que por cada 20.000 almas o aproximadamente a este número, se eligiese un diputado para la junta: que por cada diputado se eligiesen cuatro electores, en razón de uno por cada 500 habitantes: que en los distritos de las ciudades y villas se hiciese el nombramiento de electores por mayoría absoluta de los votos de todos sus vecinos, y en los partidos foráneos en que no es fácil reunir aquellos por la distancia de los pueblos, se hiciese por nombramiento de electores elegidos en las parroquias, en razón de uno por cada cien vecinos o quinientos habitantes, o próximamente a este numero. Regulándose, pues, la población de aquella provincia en 220.000 habitantes, se determino que se nombrasen doce diputados para componer la junta, 5 por Cartagena y su jurisdicción, dos por Tolu, dos por San Benito, dos por Mompox, y uno por Simiti" Acta de la Junta Suprema de la Ciudad y Provincia de Cartagena. ff. 15-19. Diciembre 11 de 1810, Archivo Restrepo R. No 5, Vol. 9-14, f15 v y 16 r. (CEDHIR) Pero esta decisión tropezó con unos tumultos en Mompox y en Simití que impidieron la realización de las elecciones así que se dispuso que la misma junta nombrase diputados suplentes por cada uno de los cabildos con calidad de ser relevados a medida que se eligiese a los propietarios. De esta manera se nombró, para representar al
} 
mayor una reunión con el objetivo de sacar los electores de la parroquia. Para este efecto el secretario acompañado del cura y del juez llamarían de uno en uno a los concurrentes que debían decir en voz alta su nombre y por quién votaban.

La exclusión de los vagos, domésticos y esclavos pretendió entregar el derecho de elegir a aquellas personas de reconocimiento que tuvieran independencia económica y de pensamiento y que no estuvieran subyugadas a otro. Sin embargo debido a la conformación étnica de la provincia estas elecciones estuvieron marcadas por la participación de una población conocida como "libres de todos los colores", cuestión que generó en los sectores de blancos notables la inquietud por los manejos que se podían dar a estos comicios, (Conde, 1999) no en vano ellos representaban un alto porcentaje, según el último y más completo censo del siglo XVIII la población era la siguiente:

Cuadro No. 1

Censo de población siglo XVIII

\begin{tabular}{|l|r|r|}
\hline & NUMERO DE PERSONAS & \multicolumn{1}{c|}{$\%$} \\
\hline Eclesiásticos & 424 & .4 \\
\hline Blancos & 13.426 & 11.4 \\
\hline Libres & 75.490 & 63.8 \\
\hline Esclavos & 9.622 & 8.1 \\
\hline Indios & 19.416 & 16.4 \\
\hline TOTAL & 118.378 & 100.0 \\
\hline
\end{tabular}

Fuente: Meisel, Adolfo. (1988). "Esclavitud, Mestizaje y haciendas en la provincia de Cartagena 1533-1851". En: Bell, Gustavo. El Caribe Colombiano. Selección de textos históricos. Barranquilla. Uninorte, pp. 118.

La escasez e inexactitud de los censos existentes no permiten acercarnos más a la composición socio racial de la provincia de Cartagena; sin embargo, y considerando que los datos suministrados por estos pudieron haber sido alterados por los encargados de realizarlos o por los mismos censados que se cambiaban de profesión, arte e incluso color de piel. ${ }^{9}$ Según el censo citado en 1777 la población de la provincia de Cartagena era de 118.378 almas, donde una inmensa mayoría 75.490 estaba compuesta por pardos, zambos, mulatos, negros libres, blancos pobres y toda suerte de combinaciones, que el

\footnotetext{
circuito de Cartagena provisionalmente a: el canónigo Don Juan Marimon, a Don José Ignacio de Pombo, el doctor Manuel Benito Revollo, Don Joaquín Villamil y Don Juan de Dios amador; por San Benito Abad a Don Antonio Madarriaga y Don Tomas Andrés Torres; por Mompox, a Don Cayetano Revueltas y Don José María del Real: por Simiti, a Don Teodoro Escobar, y como secretario inamovible, Don José María Benito Revolllo. ezequiel corrales, Manuel (comp.), Documentos para la historia de la provincia de Cartagena de Indias, hoy Estado soberano de Bolívar en la unión colombiana, 2 vol. Bogotá, Imprenta de Medardo Rivas, 1883, p. 182.

${ }^{9}$ La visión del otro y como se ve a sí mismo son los elementos que delimitan el color de la piel, de esta manera alguien se podía reconocer como pardo, zambo o blanco independientemente de la tonalidad de su piel, es decir que la condición racial era más social que étnica.
} 
empadronamiento recoge bajo el título de "libres" y que representaban un 64\%; promedio superior al del resto de la nueva granada. Mientras que 9.622 negros esclavos representaban el $8.1 \%$ y 19.416 indios correspondían al $16.4 \%$. La población "blanca" era el $11.4 \%$ con 13.426; en Cartagena más que en cualquier otro lugar de la Nueva Granada este título era gelatinoso y podía incluir a mestizos u otras combinaciones que habían podido comprar sus títulos, o ascender social y económicamente a través del matrimonio, las milicias o la política. ${ }^{10}$ (Carmagnani, 2004), (Kuethe, 1993), (Marchena, 1982)

Teniendo en cuenta que la población de la provincia no creció a un ritmo muy acelerado desde finales del siglo XVIII y principios del XIX, la composición social durante el período de las independencias debía ser muy similar ${ }^{11}$, además hay que tener en cuenta que la mayoría de la población era libre y muchos de ellos pertenecían a las milicias por lo que poseían fueros y privilegios. En este sentido existió desde un período muy temprano de la vida republicana de la provincia de Cartagena la preocupación por la participación que debía dársele a unos sectores sociales que en teoría ya eran libres y que en el nuevo sistema político debían tener derecho a sufragio y ser considerados iguales en derechos ante la ley.

Sin embargo, no fue fácil mantener estas disposiciones, la participación o no de los sectores populares en los comicios generó muchas y acaloradas discusiones en torno al ejercicio de los derechos políticos. La sociedad cartagenera del primer cuarto del siglo XIX llenó de contenidos el término "ciudadano", adaptando la definición de las teorías liberales contemporáneas a la realidad de la provincia. Sumados a la condición de vecino, la edad y la naturaleza, establecidos en las distintas constituciones provinciales, estuvieron valores como el patriotismo, la fidelidad, el republicanismo y el honor llenando de contenidos la digna condición de ciudadano. Así desde muy temprano se planteó la discusión en torno a la pregunta de si los sectores populares podían sufragar. José Fernández de Madrid y Castro y Manuel Rodríguez Torices y Quiroz en uno de los primeros periódicos políticos que circuló en la provincia de Cartagena, pregonaban el peligro que significaban

[...] las elecciones que emanan inmediatamente del pueblo, porque este en primer lugar no se halla en estado de discernir quales sean los individuos más dignos de exercer tan arduo y delicado ministerio; $y$ en segundo lugar porque el partido de los intrigantes y ambiciosos prevaliendose del candor, ignorancia y miseria del pueblo, halla con facilidad los medios de corromperlo o engañarlo. (Argos Americano. Papel político, económico y literario de Cartagena. Cartagena, Diciembre 10 de 1810. Continúan las reflexiones sobre nuestro Estado. p. 48-49)

\footnotetext{
${ }^{10}$ Es preciso decir que muchos "blancos" compraban estos títulos ya que en ocasiones se trataba de mestizos que tras conseguir una elevada posición económica tenían el dinero suficiente para comprar algo de "prestigio". Siempre habrá dudas sobre la procedencia étnica de estos por cuanto seguramente se trata de mestizos-blancos, no desde el punto de vista étnico sino social.

${ }^{11}$ Según el censo de 1834, la provincia de Cartagena tenía una población de 130.324 habitantes incluida San Andrés, Censo General de Población de la República de la Nueva Granada, 1834. Archivo General de la Nación. fol. 32-41.
} 
Por lo que proponían que lo más conveniente para el estado de la civilización en la provincia era establecer los dos niveles de elecciones, unas primarias y otras asambleas de electores.

Seria muy útil que los vecinos antes de entregar las papeletas de nombramientos de electores y estos antes de elegir los vocales se ligasen con la santidad de juramento protextando no proceder por prevención, resentimiento, parcialidad, ni otro motivo alguno que el bien estar y regeneración de la patria, cuya $f[s]$ uerte tiene en sus manos. ¿Qué más seguro garante puede esperarse de un pueblo timorato y religioso? Verificado el nombramiento de los electores, deberán estos juntarse y proceder con la mayor brevedad a la elección de los vocales a fin de no dar lugar ni tiempo a la intriga para disponer y dirigir sus criminales manejos. (Argos Americano. Papel político, económico y literario de Cartagena. Cartagena, Diciembre 10 de 1810. Continúan las reflexiones sobre nuestro Estado. p. 48-49)

Para Fernández de Madrid y Rodríguez Torices, todo ciudadano debía tener voz activa y pasiva en la marcha de los negocios públicos, ya que esa era la única manera de convertir a los antiguos vasallos del rey en ciudadanos de la Nación. Hasta el año de 1816, "todo ciudadano por infeliz que sea" debía disfrutar del derecho del sufragio y a partir de ese año, "un censo general del estado de los bienes de cada ciudadano" permitiría establecer quienes seguirían gozando de dicho derecho (Argos Americano Papel político, económico y literario de Cartagena. Cartagena, Noviembre 12 de 1810. Continúan las reflexiones sobre nuestro Estado. p. 37. No. 9). Pero como podían ser muy arriesgadas las elecciones que emanaran directamente del pueblo entonces era mejor establecer los distintos niveles electorales.

Sin embargo, no todos estaban de acuerdo en permitir el ejercicio del derecho al voto a las castas o al "populacho" señalando como argumento la falta de formación, educación y la ignorancia que tenían estos hacia el gobierno representativo. Así lo manifestó Bolívar cuando preocupado por las elecciones populares dijo:

\begin{abstract}
Las elecciones populares hechas por los rústicos del campo, y por los intrigantes moradores de las ciudades, añaden un obstáculo más a la práctica de la federación entre nosotros; porque los unos son tan ignorantes que hacen sus votaciones maquinariamente, y los otros, tan ambiciosos que todo lo convierten en facción; por lo que jamás se vio en Venezuela una votación libre y acertada; lo que ponía el gobierno en manos de hombres ya desafectos a la causa, ya ineptos, ya inmorales. El espíritu de partido decidía en todo y, por consiguiente, nos desorganizó más de lo que las circunstancias hicieron. Nuestra división, y no las armas Españolas, nos tornó a la esclavitud. (Bolívar, 1812)
\end{abstract}

Bolívar, como muchos otros, comprendía que se trataba de instalar un sistema nuevo a unos territorios y una sociedad que habían vivido trescientos años de "oprobio y oscuridad" y que la instauración de un sufragio amplio debería ir acompañada de un proceso de educación moral y religiosa ya que según él, sólo un pequeño puñado de hombres poseían las virtudes necesarias 
para comprender el valor del sufragio. A fines de la década del 20 un importante dirigente probolivariano fue más tajante aún al rechazar la decisión de igualar al "bajo pueblo" con las personas más ilustradas, según él al otorgarse los mismos derechos a todos los individuos, se rompió con las leyes naturales "que nos hacen a todos desiguales" y se generaron todos los desmanes y conflictos que han azotado a la república en los últimos años.

\begin{abstract}
Pero bajo una u otra forma de gobierno, en las provincias donde se adoptó la federación, como en aquellas que establecieron una autoridad central, se dio a las ideas la dirección más democrática. Sea efecto de la natural tendencia que tienen los hombres a pasar de uno a otro extremo, sea que los campeones de la independencia conociesen que, a falta de ilustración, era necesario hablar a las pasiones para poner en movimiento una masa tan inerte, para arrancarla de su obediencia pasiva, y para sostener con sus brazos la revolución, ello es que nuestros gobiernos, como también los escritos que se presentaron osados en la arena a defender con su elocuencia la causa de la patria, y a manifestar la justicia que la asistía, ostentaron todos el republicanismo más desenfrenado. Proclamóse como el primero de los dogmas políticos, la primera de las quimeras en lo físico y moral: la igualdad de los niveladores. En vez observar las leyes de la naturaleza, que ha hecho desiguales a los hombres mediante una distribución más o menos liberal de sus dones y favores; en vez de aquella igualdad del punto de partida, que permite a cada cual colocarse según su mérito y utilidad, y que es la única que existe, y puede existir en una sociedad bien organizada, se dio a esta idea una latitud monstruosa y absurda, pretendiendo someterlo a todo a la misma medida. Junto con ella, se invocaba a cada paso a la libertad; a la libertad, cuyo nombre es tan dulce, pero cuyo uso es tan difícil; y abusando lamentablemente de ambas cosas, se desencadenaron todos los elementos desorganizadores, y se suscitaron borrascas de la más turbulentas democracia. (García del Río, 1985)
\end{abstract}

Como señaló García del Río, el proceso de reconocimiento de la igualdad fue muy complejo en una sociedad que era tradicional y como tal conservaba una división en clases, estamentos y cuerpos, cada uno con privilegios y fueros especiales que no podían desaparecer de un día para otro. Por lo que, la instauración legal del principio de igualdad, chocó con la realidad de una sociedad desigual y que se oponía a eliminar los privilegios de clases. El principio mismo de la ciudadanía política requería de la existencia de una serie de contenidos de "probidad, patriotismo y virtudes cívicas" las cuáles se señalaban como ausentes en el bajo pueblo y las castas, mientras que los notables eran los únicos poseedores de tales características. Los legisladores, mencionó García del Río "no calcularon que en una sociedad como la nuestra, compuesta de elementos discordes donde era tan grande la desigualdad de condiciones, donde la masa era tan indiferente a todo, menos al reposo, donde existía tanta inhabilidad política, era conveniente dar vigor a la autoridad y aun renunciar a algunos derechos [...]". García del Rio, 1985, p. 42) La igualdad racial había sido el centro de la Primera Independencia de Cartagena y Mompox. Después de que la Gran Colombia ganó su independencia en 1821, la igualdad continuo siendo una idea movilizadora, pero, a medida que la guerra fue cediendo, el concepto de igualdad para todos los hombres que 
demostraran civilización, luces e independencia económica desplazó los logros militares (Helg, 2004, p. 163)

Para evitar la injerencia directa de los sectores populares en los comicios los legisladores reunidos en Cúcuta establecieron que las elecciones estaban divididas en dos niveles unas primarias o parroquiales, que tenían una base amplia de participación ya que permitía votar a todos los varones colombianos que: tuviesen cumplidos 21 años de edad o estuvieran casados y tuvieran una propiedad de 100 pesos. Y unas elecciones secundarias cuya base era mucho más estrecha conformada por los electores, cuyos requisitos eran saber leer y escribir, tener 25 años cumplidos, ser propietario y vecino ${ }^{12}$. Estos finalmente eran quienes elegían al ejecutivo y al legislativo. Con esto pretendieron representar el orden jerárquico de la sociedad y asegurar que los elegidos fueran los más notables.

A pesar de esto, a algunos dirigentes cercanos a Bolívar les pareció demasiado amplio el sufragio, y consideraron que la convención no le había prestado atención a los propósitos del libertador. Las elecciones solo debían recaer en personas que tuvieran las cualidades necesarias para afrontar el deber de representar a toda una Nación y sobre todo en momentos en que la ingobernabilidad era latente. Un contemporáneo advirtió que no se debía caer en calentamientos republicanos y demócratas al punto de elegir a cualquiera para los altos cargos de la Nación.

[...] la política, dice un autor, no puede ser jamás una ciencia popular, ni aun en los gobiernos más libres. Siempre hay mucho de ilusorio en la idea de que un pueblo conduce él mismo sus negocios. Es, por tanto, absurda la pretensión de que todas las clases participen indistintamente del derecho de intervenir en los negocios de la comunidad. Lejos de ello, es necesario limitar este derecho a ciertos actos; no conceder el de votación sino a los que tengan ciertos requisitos indispensables. La noción del sufragio universal es perjudicialísima. "el derecho que un hombre posee con derecho a votar, es un derecho artificial; y no debe ser otro que el que las leyes le conceden. El sufragio universal está calculado para producir y alimentar opiniones violentas y servil dependencia, para dar en tiempos de quietud una gran preponderancia a la riqueza, y en tiempos de disturbios un poder adicional a los demagogos ambiciosos. El es la tumba de toda libertad moderada, la cuna de la tiranía y la licencia. (García del Río, 1985, 182-183)

Pero no todos consideraban que era necesaria la exclusión del derecho de voto a los sectores populares, otros dirigentes creían en la necesidad de interesar a estos por el desarrollo del Estado y que la única manera de llevarlo a cabo era a través de su participación en las urnas. La gente en general, argumentaban algunos liberales, era ajena a los asuntos políticos y permanecía atenta a sus negocios, lo que la hacía fácilmente manipulable. Otro contemporáneo señalaba: "Las luchas eleccionarias han sido muy fecundas en conflictos en Colombia [...] Las multitudes o no lo poseen -el sufragio- de derecho o no lo ejercen en realidad por que no tienen conciencia del valor de la

\footnotetext{
${ }^{12}$ Art. 21 "Constitución de la República de Colombia. 30 de agosto de 1821”. En: Uribe Vargas Diego Las Constituciones... Vol. II, p. 810.
} 
votación o apenas funcionan como ciegos instrumentos de poder o de los intrigantes ambiciosos". A su vez este prolífico escritor manifestó la necesidad de ampliar el sufragio y de proteger su libertad. También señalaba la necesidad de reconocer que "el sufragio no será de verdad una institución fecunda, sino a condición de ser directo y secreto - restringido solo a los alfabetos sin otra condición- solo así [...] las elecciones serán sinceras y el triunfo de las causas políticas no será obra del clero, del ejército y de la policía, de la intriga interesada, la corrupción y la violencia" (Samper, 1984, p. 233-235).

Todas las posiciones en pro o en contra de la participación de los sectores populares en los comicios tenían como objetivo impedir o utilizar para sí mismo, una fuerza electoral importante y que podía inclinar la balanza a favor o en contra de uno de los bandos en disputa. Los votos eran necesarios para cualquiera que quisiera obtener un cargo en el legislativo, así que estos no se podían despreciar, así proviniesen de vagabundos, lo que había que hacer era buscar la manera de cautivar a los posibles sufragantes, sin importar si estos cumplían o no con los condicionantes impuestos por la legislación, ya que la decisión final de quien podía sufragar pasaba por la relación que tuvieran los sufragantes con un notable y a su vez la posición de éste último frente a los miembros de las juntas parroquiales y jueces encargados de definir la condición de ciudadano-vecino de un habitante, de la cual muy seguramente el hacia parte.

Al tiempo que se discutía sobre el problema de la definición del ciudadano, y de los mecanismos de inclusión/exclusión, los notables cartageneros se enfrentaron al dilema de tener que buscar votos para obtener espacios de poder en las cámaras provinciales o en el gobierno nacional, por lo tanto debieron recurrir a algunas prácticas que en no pocas ocasiones fueron señaladas por los escritores y periódicos de la época como actos atentatorios contra la libertad del sufragio, generando intensos debates políticos. A continuación describiremos algunas de estas prácticas, señalando la importancia que el voto tuvo para la sociedad cartagenera.

\section{Los militares deben votar... y deben hacerlo bien}

La Constitución de la Gran Colombia, emanada del Congreso de Cúcuta de 1821, disminuyó los requisitos socioeconómicos del sufragio capacitario y suspendió los privilegios militares. Los miembros del ejército podían votar en las elecciones primarias. Muchos no votaron en las elecciones de 1822, por lo que en 1825 el gobierno expidió una orden que buscaba impulsar el sufragio de los integrantes de la guarnición, al tiempo que trataba de evitar que remociones de la tropa dieran lugar a dobles votos. (Obando, 1835, p. 2)

La constitución de 1832 estableció como requisitos para poseer el derecho al sufragio en las elecciones parroquiales una edad mínima de 21 años, la independencia económica o subsistencia asegurada sin sujeción a otro en calidad de sirviente o jornalero y saber leer y escribir (pero esta se aplaza para $1850)^{13}$. El carácter más liberal de las instituciones y la reacción a la época

\footnotetext{
${ }^{13}$ Art. 8. "Constitución del Estado de la Nueva Granada. 29 de febrero de 1832". En: Uribe Vargas, Diego. Las Constituciones de Colombia... Vol. II, p. 895.
} 
bolivariana justificaron la aclaración sobre la condición ciudadanía de los militares, la abolición del fuero y su derecho de sufragar como individuos ya que el voto no era parte del fuero militar ya perdido, sino un derecho ciudadano (López, 1833, p. 11-12). A diferencia de los primeros años de vida independiente, los militares tenían la facultad de votar como los demás ciudadanos. Con este cambio surgen inquietudes sobre la aptitud para votar de los integrantes más bajos de la tropa. En 1832 el gobierno puso en claro su derecho. El prest, pre o pago que recibían los soldados por su servicio aseguraba su capacidad económica para sufragar. (Pinzón de Lewin, 1994)

El argumento sobre el que se sostuvo la idea de que los soldados tenían derecho a voto, era que la carta del 32 a diferencia de sus predecesoras no exigió la tenencia de ingresos ni de propiedad para acceder al derecho de sufragio, lo que en teoría permitió que votaran quienes tuvieran unos ingresos suficientes para poder vivir. Sin embargo, las múltiples interpretaciones que tuvo la ley trajo confusiones en torno a la definición de "subsistencia asegurada" sobre todo cuando se trataba de definir el voto de la tropa "por que no había duda en que estos tenían asegurada su subsistencia con el servicio que se presta en la noble carrera militar". Pero por otra parte se hacía fuerte "el inconveniente de la influencia de los jefes en individuos que en lo jeneral carecen de nociones sobre la importancia i libertad del derecho de sufrajio". (Semanario de la provincia de Cartagena, Cartagena, 12 de noviembre de 1843 , no. 70 . p. 2).

Es decir, que la existencia de los ingresos necesarios no era condición para que existiera independencia política, así por ejemplo se manifestaba que "un jornalero tenía más independencia de opinión que los soldados y marineros y que muchos dedicados a otras profesiones". (Semanario de la provincia de Cartagena, Cartagena, 14 de mayo de 1840, no. 68. p. 3). Lo que se buscaba con el requisito del ingreso era conservar la libertad del sufragio, sin embargo en el caso de las elecciones de 1829 se notaron los inconvenientes para definir la independencia de los individuos de la tropa, ya que si bien estos poseían los ingresos necesarios para su subsistencia, tenían una dependencia de su jefe superior a quien debían respeto y obediencia. Obediencia que llegaba incluso a la obligación de votar por quien señalara el superior, así lo demuestra en una carta enviada por el comandante general de la provincia de Cartagena Mariano Montilla al conde de Adlercreutz comandante militar de Mompox:

Hablé a usted el correo pasado de elecciones, vuelvo a hacerlo ahora llamando la atención de usted sobre ellas, no sea que vayan a ganarnos de mano. Repito que los sargentos 1os deben no solo votar, sino ser obligados a ejecutarlo. ("Mariano Montilla a Coronel Federico de Adlercreutz, Cartagena Mayo 2 de 1829" Adlercreutz, 1928, p. 88-89)

En los comicios de 1834 también se hizo presente el inconveniente de la definición de quiénes tenían derecho al sufragio. Desde su periódico "El termómetro político de la Costa" Eusebio María Canabal expresaba su preocupación por que en las elecciones primarias de este año, habían sufragado los soldados en virtud de una declaratoria expedida por la administración de José Ignacio de Márquez el 2 de julio de 1832, tal vicio como era señalado por el editor cartagenero debía ser corregido porque es contrario 
al espíritu de la constitución que, suspendía de la ciudadanía (y en consecuencia del derecho de ser sufragante parroquial) a los jornaleros y a los sirvientes domésticos; probablemente -señalaba el dirigente político- porque estaban sujetos a una dependencia que podía comprometer la "dignidad de la ciudadanía". Así las cosas, se juzgaba que si estos argumentos eran justos con respecto a los artesanos a quienes se privaba del ejercicio de los derechos políticos, debía "aplicarse con más razón á los soldados, porque están constituidos en una dependencia más completa y permanente, y de más difícil remedio, en fuerza de las severas leyes que proveen a la disciplina militar". En definitiva, señalaba Canabal que:

No habrá quién no esté persuadido de que un artesano, ó menestral, ó un sirviente doméstico, disfrutan, en todas partes, de una independencia de opinión, mucho mayor que la que poseen los soldados, que se habitúan a la ciega obediencia, y están constantemente temiendo que se les impongan castigos arbitrarios por sus superiores. (El termómetro político de la Costa, Cartagena, junio 25 de 1834, No. 12 p. 1)

Las elecciones de 1834 fueron de las más disputadas del período de estudio, la gran cantidad de páginas que se publicaron en los periódicos locales, así como las hojas sueltas que circularon en la provincia así lo demuestran. También parece que se presentaron irregularidades en el ejercicio del sufragio. Tal como era frecuente, todos los bandos en disputas se acusaban mutuamente de haber cometido actos "escandalosos" o "atentatorios contra la seguridad pública" como se les denominaba a lo que después conoceríamos como fraudes electorales (Posada, 2000). El mismo Canabal señaló que a pesar del vivo interés en estos comicios los electores fueron elegidos por la tropa y fueron anulados los votos de la mayoría de ciudadanos. Pero ¿cómo se dieron los votos de los soldados y por quienes votaron?:

Un sargento, cabo o pito se ha puesto detrás de cada soldado á decirle el nombre de cada uno de los que estaban en una lista impresa y que se fijó en las esquinas, que se repartía en los pueblos y en los cuarteles y que comenzaba por Dr. Miguel Tobar, y acababa por Ignacio Morales. Hubo soldados tan torpes, que fue imposible que pronunciasen ciertos apellidos, v.g. Cuenca, y López Aldana, pues innumerables ciudadanos se reían al oír los disparates que pronunciaban, diciendo culeca, lo que es Aldaba, lo que es jarana. [...] ¿No habría sido mejor que se les hubiera dejado votar libremente por los gefes y oficiales de la guarnición á quienes conocen, de quienes han recibido la instrucción militar, y con quienes han partido de las glorias, y las penas en el campo de batalla? [...] ¿Semejantes votos no habrían sido emitidos con la libre voluntad, con que no han sido dados por sugetos que en las mismas elecciones preguntaron al mismo soldado si los conocía, y respondía que no? No hay duda que el que mando formar la lista, no lo animaba el noble sentimiento de que el soldado votara, sino de que le sirviera de un ciego instrumento, que hiciera electores a ciertos ciudadanos, y si no dígasenos ¿por qué estando en la lista los señores Flores, Ricaurte, Groot, Leyva, Zuleta, Acevedo y Lora, no han votado todos los soldados por ellos, y han logrado salir electos? Ahi no se nos haga tan bochalemas [sic] tan batuecanos [sic], pues esos nombres se pusieron para fascinar a los tontos para dorar la píldora, y ellos en la lista han sido lo que el siete de oros en la basiga. (El termómetro político de la Costa, Cartagena, julio 16 de 1834, No. 15 p. 3-4) 
De igual manera, en 1849, un periódico de filiación conservadora denunció la expulsión de las filas militares del sargento Enrique Ruiz perteneciente al batallón $7^{\circ}$, según ellos por haber sufragado en las elecciones por la lista de los candidatos "del orden o conservadores". Señalaron que "de igual clase, Manuel Urruchurtu ha estado en el calabozo, por resistirse a votar por la lista roja, hasta ayer que se le puso en libertad para mandarlo a una comisión a Pasacaballos, esto es lo que puede llamarse una democracia modelo!!" denunciaron así las supuestas arbitrariedades de los "rojos" liberales en contra de la libertad del sufragio. (El porvenir periódico de la juventud, Cartagena, 5 de diciembre de 1849, No 16. p.3.)

Pero cuál era el inconveniente en que votara la tropa, se intentaba proteger la libertad del sufragio, o sólo era una argucia para reprochar un comportamiento que traería consecuencias desfavorables para los objetivos políticos de los serviles. El político liberal Manuel Marcelino Núñez se preguntaba desde su tribuna política “¿Por qué los serviles gustan tanto de la ley del embudo cuando pretenden que ahora no suceda lo que a Marras "explicaremos" que los rasos soldados concurran como los demás ciudadanos con su voto en las elecciones parroquiales?" (El calentano, Cartagena, julio 9 de 1834 no. 10. p. 2). Seguramente -respondía Nuñez- porque para las elecciones de 1834 ellos, es decir los serviles, ya no tenía las influencias que otrora sobre algunos militares, lo que hacía que recurrieran a declarar la ilegalidad de un comportamiento del cual ellos hicieron uso durante toda la etapa que el país estuvo bajo su mando.

Sin embargo no todos los sufragios eran producto de la coacción militar o de los soldados, estos apenas eran unos dos mil en toda la República. Al margen de ésta, hubo otras prácticas políticas que permitían la consecución de votos.

\section{De cazadores de almas a cazadores de votos. Los curas y el sufragio}

Uno de los elementos que más aglutinaba a la población era la asistencia a misa. El poder que tenían los curas era reconocido por las autoridades civiles, de hecho estas recurrían al poder eclesiástico para dar legitimidad a algunos actos del gobierno, como por ejemplo durante el siglo XIX cuando se proclamaba una constitución esta era juramentada y uno de los protocolos más importantes era la celebración de una misa, TE DEUM, luces y fiestas por varios días, así mismo, durante la misa el cura párroco en su homilía hacía una exhortación a la bondad de la constitución y recordaba el deber cristiano de obedecer "tanto a las leyes divinas como a las humanas" mientras levantaba el texto constitucional. ("Boletín Publicación y Juramento de la Constitución. Archivo Restrepo, Riohacha Abril 30 de 1832". Archivo José Manuel Restrepo Rollo 5 Vol. 9-14. (ff. 479-480).

Desde mucho antes de los acontecimientos de las independencias, los curas tuvieron una influencia enorme en la vida política de las provincias, sin embargo con el cambio acaecido tras las revoluciones muchos se convirtieron 
en abanderados de la causa republicana y defendieron tanto desde la iglesia como con las armas la causa libertadora.

Pero el poder de estos llegaba más allá, el púlpito era utilizado tanto para catequizar en lo divino como en lo terrenal, la política invadía el atrio de la iglesia, de hecho muchas de las asambleas parroquiales se llevaban a cabo al interior de ellas y los curas pasaban fácilmente de cazadores de almas a cazadores de votos ${ }^{14}$.

En 1834, el dirigente liberal Juan José Nieto desde su órgano de difusión acusó a los serviles por hacer uso de una religión que según este, ni ellos mismos respetan y atienden únicamente con el objetivo de ganar votos para su causa:

[...] mientras que allá entre sus pechos no conocen ni respetan a la religión que ellos mismos hipócritas profanan al invocarla cuando la necesitan, se valen de sus ministros engañados, de los curas para seducir al pueblo y estorcionarlo para que de sus votos para la representación nacional a los enemigos tan conocidos de la patria y del gobierno. (El Cartagenero, Cartagena, 5 de abril de 1834, No. 6. p. 2)

En el periódico liberal "El cachaco" publicado en Bogotá por Lorenzo María Lleras y Florentino González y en el que también participaba el presidente Santander, denunciaron la circulación de unos papelitos del provisor de Cartagena "escrito a los curas para que sedujesen al pueblo a fin de que reeligiese al Dr. Castillo para senador" (El Cartagenero, Cartagena, 25 de junio de 1834, No. 13. p. 4). Se menciona en este que:

Aquí [en Bogotá] dicen los bolivios que vendrán de senador por Cartagena, Castillo y Canabal: y Gori a la cámara de representantes, Ustedes lo verán.- ¡que tres niños!

Según esta esperanza parece que no faltará ahora también por ahí alguna otra cartita pastoral y apostólica para los curas de esta provincia recomendando a esos marchantes. Lo veremos $-y$ entre tanto cooperemos a que llegue aquel día dichoso en que se destruya ese pernicioso influjo del clero en nuestros negocios públicos. Ese día podremos decir. ya hay libertad. (El Cartagenero, Cartagena, 25 de junio de 1834, No. 13. p. 1)

Empero, no todos rechazaban la presencia de los curas en política, de hecho algunos fueron presentados como candidatos para diputados. En una carta enviada por Mariano Montilla al comandante militar de la provincia de Mompox le recomendaba a este que cuidara que los resultados de las elecciones para diputados les fuesen favorables y no ocurriera el desastre de las anteriores, es decir que no salieran electos Troncoso y Pino, le decía además que el doctor Revollo "tampoco sería malo, y reuniría mucho voto, pues fue, y es cura de esa ciudad y lo aprecian bien" ("Mariano Montilla a Coronel Conde Federico de Adlercreutz, Turbaco 28 de abril de 1829".

\footnotetext{
${ }^{14}$ Aunque dicha práctica parece haberse desarrollado más en las zonas rurales, también se dio en ciudades importantes como Bogotá y Cartagena.
} 
Adlercreutz, 1928, p. 86-87). Unos días después y viendo la dificultad de obtener un triunfo electoral el mismo Montilla le recordó la necesidad de que:

[...] se presente de candidato al doctor Revollo, a Carlos Jiménez, a Piñerez; y muy bueno sería Troncoso el de Ocaña: vea usted bien que el nombramiento de Ribón conviene o el del señor Serrano o el de algún clérigo machucho, apóyelo siempre con preferencia a los conocidos trabucos y últimamente observe usted mucho las intrigas de los contrarios y las informalidades que se cometan para decir de nulidad inmediatamente. (Adlercreutz, 1928, p. 90-91)

Al mismo tiempo le indicaba la forma como debía obrar en caso de no poder triunfar, la estrategia era clara, o se obtenía un triunfo ó no había elecciones. "Se asegura que el doctor Troncoso sobre Trabuquero se recibió de ciudadano inglés en Jamaica a la par de su cuñado Torres, y aunque yo no tengo el reglamento a la vista me parece este un legal impedimento. En fin usted está en esa provincia y es honor suyo que haya buena elección o ninguna, pasan las cosas cada día van marchando a un desenlace final" (Adlercreutz, 1928, p. 90-91).

A diferencia de la influencia que podía ejercer el oficial a cargo de una tropa sobre sus subordinados durante el ejercicio electoral, en el caso de los curas y párrocos su influencia estaba legitimada por las leyes divinas y ellos podían hacer uso de ellas recomendando desde el púlpito a sus fieles que votaran por el candidato de su preferencia, además teniendo en cuenta que el mismo poder civil les otorgaba legitimidad al concederles participación en sus obras terrenales estos tenían aun más justificación para sus actos.

En las elecciones de Arjona, distrito de la provincia de Cartagena los resultados electorales de los comicios de 1831 no favorecieron al gobierno "extraordinario", de Mosquera a pesar de que un oficial del Estado mayor, al parecer introdujo un papelito con unas recomendaciones para los sufragantes, que estos desobedecieron porque acataron las ordenes del cura de la parroquia, por lo que desde Bogotá rayos se lanzan desde el gabinetillo contra las elecciones de Arjona, contra su párroco, atribuyéndole que había arrastrado con la ASAMBLEA a su casa para que los sufragantes se plegasen a sus ideas.

Pero ¿cuánto podía influir un cura entre sus feligreses? Teniendo en cuenta que se trataba de una sociedad extremadamente tradicional, con una transición muy reciente al sistema republicano seguramente que era mucha la influencia, sin embargo la prensa periódica y las hojas sueltas generaban también un aire de discusión que permitían la toma de decisiones sobre la base de argumentos de otro tipo. En este sentido la existencia de unos espacios públicos de discusión, de una opinión pública que podía tener alguna influencia entre la sociedad, y la presencia constante de intermediarios políticos ${ }^{15}$ reclutando

\footnotetext{
${ }^{15}$ Los intermediarios eran aquellos personajes que no eran parte de la plebe ni de los notables y que servían de bisagra entre unos y otros. Algunos de ellos eran mulatos o pardos, milicianos con importante participación durante las independencias o en las firmas de las constituciones y se movían con facilidad entre la plebe. Acerca de los intermediarios culturales ver Burke, 1991, pp. 115 et passim. Aunque quién introdujo el término para América latina fue Carmagnani (1998, pp. 7-16).
} 
clientelas electorales entre los distintos sectores sociales y en los rincones más apartados de la provincia de Cartagena, permiten crear una imagen de una sociedad que era capaz de negociar su participación en las lides electorales porque sabían (la presencia de dirigentes en sus parroquias y distritos en busca de votos así se lo demostraban) que su voto tenía un valor de uso y que este le podía significar unos recursos económicos, sociales o políticos a través de una negociación con los intermediarios políticos.

\section{Comida, aguardiente y votos. Negociando el voto}

Pero no todos los sufragantes eran soldados o pertenecían al cuerpo militar, ni todos los votos eran conseguidos a través de la fuerza de las armas o de los catecismos de los curas. Entonces, ¿cuáles eran las motivaciones para participar del sagrado acto del sufragio? ¿Por qué la gente participaba en él? ¿La sociedad cartagenera en general vio en el sufragio una forma de intervención deseable?

Los relatos de la época describen un ambiente electoral acalorado, siempre con unos bandos en disputas que competían por el control del poder local, Sin embargo no faltaban las quejas por la falta de "espíritu público" de la ciudadanía que no prestaba atención al desarrollo de los acontecimientos políticos más notables. En las elecciones participaban todos los sectores sociales habilitados o no para el ejercicio del derecho al voto, constantemente las editoriales de los periódicos utilizan términos como "populacho" o "bajo pueblo" de manera despectiva para referirse al uso que la facción ganadora hizo de estos en los comicios, mientras que los ganadores se refieren a este mismo actor social como "El pueblo se expresó" "La grandeza del pueblo" para ejemplificar que estos cuentan con la mayoría electora ( El tribuno del pueblo. Cartagena, julio 17 de 1836.- imprenta de E. Hernández. y Ciudadano Fidel, Cartagena 10 de mayo de 1849, imprenta de E Hernández). En ambos casos el pueblo es el depositario de la soberanía y es él quién otorga legitimidad al poder político. Así que de alguna manera había que recurrir a este para obtener un triunfo eleccionario. En unas hojas sueltas que circularon en la provincia de Cartagena a mediados de 1836 se establecía un diálogo entre un anciano servil y un joven liberal en el que se describía las prácticas que tanto los partidarios de la candidatura de Obando como los de Márquez a la presidencia habían hecho para alcanzar el triunfo en las elecciones de ese mismo año. Abusando de la paciencia del lector nos permitimos insertar una narración que aunque un poco extensa y cargada de sarcasmos, nos indica algunas de las formas como se movilizaba y cautivaban a los sufragantes cartageneros en la primera mitad del siglo XIX en la provincia de Cartagena.

[Anciano servil] S. Como no sabes. ¿Pues que, ignoras, que ahora pocos días ha salido un impreso manifestando los paseos que para aunar la votación han hecho a la provincia Bustos [posiblemente se refiere a Miguel A. de Bustos], Núñez [Manuel Marcelino], Manuel Gregorio González, Vicente Díaz y otros?

[Joven liberal] L. no señor, no ignoraba tales paseos, aunque esos señores no han ido a solicitar votos para ellos mismos; pero también sé que en los 
primeros días del mes de mayo estuvieron en Santa Rosa un Dr. Ríos y un señor Luis Porras catequizando a los señores Corrales y Montalvo para ganar los sufragios de aquella población: que poco después volvió solo el señor Porras ofreciendo a un ciego Hernández que tiene allí prestigio, dos vacas paridas, unas medicinas, y pagar al Dr. Mister Ewen para que le volviese la vista. Con tal que se ganase la votación; que con este mismo objeto habló a otro vecino Padilla ofreciendole servirlo y recoger a uno de sus hijos para educarlo en su casa: que en prueba de sus ofertas le regaló tres varas de cotin para una chaqueta, y en fin mi buen amigo, que viendo Porras lo poco que valían sus obsequios y ofrecimientos para destruirla espontánea votación de aquel pueblo, envió el 16 de los corrientes, a las diez y media de la noche a su esclavo José Florencio con un pliego para el Sr. Corrales, un poquito de numerario y unos madapollanes [sic]viejos ("DIALOGO entre un joven liberal y un anciano servil. Cartagena, Junio 19 de 1836, Impreso por J. M. Angulo", BNC, Fondo Pineda 803 [243])

Tanto los recorridos que por los distintos rincones de la provincia realizaban los dirigentes políticos en busca de votos para el candidato de sus preferencias, que se constituía en sí como una novedad dentro de las prácticas políticas de la época; cómo las estrategias de negociación que se llevaron a cabo con el objetivo de ganar adherencias a la causa; nos permiten demostrar la existencia de unas redes sociales compuestas por los dirigentes políticos que en su mayoría hacían parte de los "ciudadanos notables" pero que en el nuevo rol que el sistema representativo impuso a partir de 1812, se vieron en la necesidad de negociar con sectores de la sociedad no pertenecientes a las capas altas sino por el contrario personas de los sectores populares que gracias a su servicio en las milicias, en las guerras de independencia o por el establecimiento de alianzas matrimoniales o económicas adquirieron cierta movilidad social que les permitió establecer relaciones tanto con los sectores del bajo pueblo como con los notables locales. (Carmagnani, 1998, p. 5) (Saether, 2005). A estos último se refiere Marcelo Carmagnani como los "ciudadanos intermedios" pero aquí llamamos "intermediarios políticos" ya que su labor era la de establecer relaciones de poder/influencia dentro de las sociedades locales. Tal como lo muestra de una manera caricaturesca el diálogo citado anteriormente.

El intermediario político fungía como capitán electoral, generalmente tenía contactos entre los sectores populares, era muy probable que fuera pardo o mulato y mantenía relaciones con los notables locales, formando una redes de clientelas que crearon la necesidad de querer pertenecer a ellas, ya que esto le aseguraba al cliente, "reconocimiento" y en determinado momento éste sabía que podía recurrir al patrón en busca de apoyo económico o político.

También eran frecuentes las reuniones con fines electorales, en estas se repartía aguardiente y comida a todos los asistentes a la vez que se aprovechaba para comprometerlos a votar por una lista. En una hoja suelta que circuló en la provincia de Cartagena con motivo de las elecciones de 1836:

Se dice que con mucha frecuencia se hacen en el barrio de Santo Toribio cenas costeadas por los Medranos á la que se asegura se invita a concurrir unos pocos artesanos, y algunos, o todos los que bombean en la tienda. 
Se dice que el objeto de esas cenas, es el de ganar sufrajios para las próximas elecciones a cambio de comida y aguardiente $[\ldots]^{16}$. (El Vigilante № 1, Cartagena, Mayo 15 de 1836. Imp. por Eduardo Hernández. BNC, Fondo Pineda 256 [87])

El documento alertaba a la policía sobre las cosas que hacían los serviles. Sobre todo los Medranos quienes eran abiertamente partidarios de la candidatura de José Ignacio de Márquez. Aunque no existen muchas narraciones de las prácticas del voto durante los días de los comicios, las leyes nos permiten percibir la existencia de la compra de votos. La constitución de 1821 estableció como causal de pérdida de la ciudadanía el "vender su sufragio o comprar el ajeno [...] en los fallidos fraudulentos"17. Las constituciones de 1832 y 1843 ratificaron esta medida. Lo que implica comprender que las sociedades entendían el significado del sufragio y por esto le asignaban un valor de uso, lo que sucede es que el significado que ellas le daban no siempre coincidía con el que pregonaba la teoría política contemporánea. De esta manera la venta del voto más que un ejercicio de desprecio al mismo, implica un conocimiento de causa, que nos lleva a entender que las personas sabían que su voto era importante para alguien. (Irurozqui, 2000)

Así que si bien, a través de los soldados y de los curas se podía tener acceso a votos, en realidad un gran cantidad de estos provenían de las negociaciones de los intermediarios y de la existencia de las clientelas políticas que permitían el mantenimiento de unas redes sociales más o menos permanentes y que aseguraban los votos necesarios para obtener el triunfo eleccionario.

\section{Conclusiones}

En definitiva el problema de quiénes podían votar tenía unos fundamentos teóricos basados en la libertad del sufragio, y en la consecuente independencia del sufragante, pero en el contexto de la sociedad cartagenera de la primera mitad del siglo XIX, esta discusión era trasladada al ámbito de las facciones en disputa ${ }^{18}$. Como señalamos al inicio, la revolución de la igualdad condujo a medidas "revolucionarias" de ampliación de la ciudadanía a través del sistema electoral y la eliminación de cargas impositivas a los indígenas. Pero después

\footnotetext{
${ }^{16}$ Los Medranos aludidos eran Rafael, juez de hecho del cantón de Cartagena, y Manuel, quien en 1839 sería juez parroquial de Santo Toribio. Eran hijos de Pedro Medrano, el artesano y dirigente del pueblo en los sucesos de la Independencia, quien acompañado de su hijo Rafael hizo parte de los defensores de la ciudad durante el sitio de 1815 y logró emigrar con su familia el 6 de diciembre del mismo año.

17 Art. 16 Constitución de la República de Colombia de 1821. En: Uribe Vargas Diego. Las Constituciones de Colombia... Vol. II, p. 810. Art. $9^{\circ}$ Constitución del Estado de la Nueva Granada de 1832". En: Uribe Vargas Diego. Las Constituciones de Colombia... Vol. II, p. 895.

${ }^{18} \mathrm{Si}$ bien algunos documentos de la época utilizan la palabra partido para referirse a agrupaciones políticas, éstas aún no se definen como colectividades homogéneas de carácter nacional, sino que obedecían a lealtades personales hacia caudillos locales o nacionales sin mayores diferencias ideológicas entre uno y otro bando. La configuración de los partidos políticos liberal y conservador se presentará en la siguiente década amén de la definición ideológica que llevaran a cabo Mariano Ospina Rodríguez, Florentino Gonzáles y Ezequiel Rojas. Ver Puentes (1961); Romero Aguirre (1947, p. 558). En este sentido, el concepto facción se acerca más a la realidad política de las alianzas, acuerdos y lealtades personales que se establecen en los inicios de la vida republicana en la Nueva Granada. Para lo de partido político ver: Delgado (1993, p. 173). Ver el concepto de fracciones de partidos en: Sartori (1994).
} 
del furor de los primeros años, hubo un retroceso en parte debido a lo que se consideraba por parte de los notables como un estado de "desorden", debido a la "irrupción" de un nuevo actor político: "la plebe", que en el contexto de la sociedad cartagenera referiría a "las castas de color". Los intermediarios políticos al establecer lazos entre negros - mulatos y blancos, se aseguraron la cooperación de los primeros y el reconocimiento por parte de los segundos, convirtiéndose en lo que un historiador llamó unas "clases medias", manteniendo la estructura de desigualdades sociales y raciales, pero negociando la igualdad política (Andrews, George p. 179-188). Los notables aunque en su mayoría rechazaron la igualdad entre desiguales no tuvieron más opción que negociar con estas "clases medias"

Así, durante la etapa previa y posterior a las elecciones se desarrollaban al interior de los periódicos y seguramente de los cafés, esquinas y calles de la provincia, discusiones en torno a los derechos políticos, que eran fundamentadas en los principios del gobierno representativo pero cuyos justificantes estaban siempre en la tradición de los comportamientos y de las prácticas que los distintos actores políticos habían llevado a cabo a lo largo de la corta vida republicana. En el caso de la votación de los soldados, no estaba en juego el principio irrecusable de libertad e individualidad que preconizaban las teorías liberales contemporáneas a la discusión, sino la posibilidad de obtener unos sufragios cautivos que de lo contrario caerían en manos de la facción opuesta. De igual manera ocurría con el papel que los curas jugaban como cautivadores de votos. Así el voto de la tropa o el de los feligreses era un gran bocado para quien pudiera captarlos.

Los debates electorales en la provincia de Cartagena tuvieron una importancia enorme en el proceso de construcción Republicana y contribuyeron a los procesos de aprehensión de los derechos y deberes ciudadanos. Las particularidades demográficas de la provincia le imprimieron una característica especial a los ideales de igualdad política y representación pregonados durante estos primeros años, el discurso fue aprehendido y adecuado a los intereses de los grupos sociales; así los notables "blancos" vieron en la igualdad un grave problema para sus aspiraciones, pero en el nuevo sistema electoral, una estrategia clave para mantener el control político local, todo dependía de su habilidad para el manejo de las elecciones; los pardos y mulatos vieron en ellas una posibilidad de reconocimiento y la materialización política de sus aspiraciones de igualdad, ellos ya eran libres, de tal manera que el otorgamiento de la ciudadanía no haría sino confirmar su importancia en la sociedad y darles una oportunidad de movilizarse en las jerarquías sociales; muchos de estos fungieron como intermediarios que no eran precisamente de la "plebe", ya que sabían escribir y eran tratados con respeto, pero tampoco eran parte de las esferas altas de la sociedad. Este tipo de individuos "intermedios", empleados del Estado algunos, parecen haber sido cruciales articuladores de la participación de la "plebe urbana" y en general de la política decimonónica en Cartagena, aunque han sido poco considerados en la historiografía $^{19}$. Sin embargo, el rol de estos se capta en todas las

\footnotetext{
${ }^{19}$ Recientemente Víctor Uribe Urán ha llamado la atención sobre un grupo de abogados formados en la década del veinte que irrumpieron en la actividad política inmediatamente después de su graduación y que ascendieron socialmente Uribe Urán , 2008.
} 
movilizaciones en los que la plebe actuó políticamente. En definitiva, el papel de estos personajes fue el de articuladores de la participación plebeya (Di meglio p. 179-180), y aunque puede ser visto este proceso como propiciador de la "democratización" de los espacios políticos, también pudieron haber frenado procesos de cambios más de fondo que involucrara a "la plebe". Entre los sectores populares es más difícil definir cómo valoraban el acto comicial, sin embargo, las fuentes consultadas permiten formarnos la idea de que estos sabían y entendían el valor que su voto tenía, no tanto como modo de participación política en un sistema representativo, que lo era, sino, porque sabían que era necesario para algún dirigente que estaba dispuesto a ofrecer comida, aguardiente e incluso a comprarlo.

\section{REFERENCIAS BIBLIOGRÁFICAS}

\section{Fuentes documentales}

\section{Archivos Consultados}

Archivo General de la Nación. Fondo José Manuel Restrepo.

Biblioteca Nacional de Colombia. Fondo Pineda.

\section{Periódicos Consultados}

Argos Americano. Papel político, económico y literario de Cartagena.

El termómetro político de la Costa, Cartagena.

El porvenir periódico de la juventud, Cartagena.

El calentano, Cartagena.

El Cartagenero, Cartagena.

El tribuno del pueblo. Cartagena.

El Vigilante Cartagena.

Semanario de la provincia de Cartagena, Cartagena.

\section{Fuentes bibliográficas}

Adlercreutz, Federico. (1928). La cartera del Coronel Conde de Adlercreutz. Documentos inéditos relativos a la historia de Venezuela y de la Gran Colombia. París: Editions Excelsior.

Annino, Antonio (coord.). (1995). Historia de las elecciones en iberoamérica. Siglo XIX. Buenos Aires: FCE, p.13.

Andrews Reid, George. (2007). Afro- Latinoamérica 1800-2000. Traducción Oscar de la Torre Cueva. Madrid: Iberoamericana, Vervuert, 149.

Annino, Antonio \& Raffaele, Romanelli. (1988). Quaderni Storici: Notabili elettori, elezioni. No. 3 Nova Serie 69. Diciembre. Bologna: II Mulino, p. 676-677. 
Annino, Antonio. (1992). "Prácticas criollas y liberalismo en la crisis del espacio urbano colonial. El 29 de noviembre de 1812 en la ciudad de México": Secuencia, México: 24, p. 121-158.

Bell, Gustavo. (1988). El Caribe Colombiano. Selección de textos históricos, Barranquilla: Uninorte.

Bolívar, Simón. (1975). "Manifiesto De Cartagena", Cartagena de Indias, diciembre 15 de 1812. En: Escritos políticos, Madrid: Alianza Editorial.

Botana, Natalio. (1977). El orden conservador. Buenos Aires: sudamericana.

Burke, Peter. (1991).La cultura popular en la Europa moderna. Madrid: Alianza Editorial.

Carmagani, Marcelo. (1998). "Elites políticas, sistemas de poder y gobernabilidad en América Latina". En: Metapolítica 2:5.

(2004). El Otro Occidente. América Latina desde la invasión europea hasta la globalización. México: F.C.E.

Carmagnani, Marcelo \& Alicia Hernández. (1999). "La ciudadanía orgánica mexicana, 1850-1910". En Sábato, Hilda (coord.), Ciudadanía política y formación de las naciones. Perspectivas históricas de América Latina. México: FCE.

Codificación Nacional, de todas las leyes de Colombia desde el año de 1821, hecha conforme a la ley 13 de 1912, años 1827-1828 (1926). Bogotá: Imprenta Nacional.

Conde calderón, Jorge. (1999). Espacio, sociedad y conflictos en la provincia de Cartagena, 1740-1815. Barranquilla: ediciones Universidad del Atlántico.

(2003). "Identidades políticas y grupos de poder en los inicios de la República". En revista Historia Caribe No 7 Vol. II, Barranquilla: p. 29-42.

Corrales ezequiel, Manuel (comp.). (1883). Documentos para la historia de la provincia de Cartagena de Indias, hoy Estado soberano de Bolívar en la unión colombiana, 2 vol. Bogotá: Imprenta de Medardo Rivas, p. 182.

Chiaramonte, José Carlos. (1997). Ciudades, provincias, estados: orígenes de la nación argentina (1800-1846). Buenos Aires: Ariel.

(2004). Nación y Estado en Iberoamérica. El lenguaje político en tiempos de la independencia. Buenos Aires: Editorial Sudamericana, 218.

Delgado, Oscar. (1993). "Dominación, Modernización y Democracia en Colombia". En Modernidad Democracia y Partidos Políticos. Bogotá: FIDEC, p. 173. 
Di Meglio, Gabriel. (2003). "La consolidación de un actor político: Los miembros de la plebe porteña y los conflictos de 1820". Sábato, Hilda \& Lettieri, Alberto compiladores. En La Vida política en la Argentina del siglo XIX. Armas, Voces y votos. Argentina: F. C. E., p. 335 - pp. 173-189.

Escalante Fernando. (1992). Ciudadanos imaginarios. México: editorial El colegio de México.

El pensamiento constitucional hispanoamericano hasta 1830. (1961).Caracas: Biblioteca de la Academia Nacional de la Historia, tomo IV.

García del Río Juan. (1985). Meditaciones Colombianas. Bogotá: Editorial Incunables.

Graham Richard. (1990). Patronage and Politics in Nineteenth-Century Brazil. Stanford.

Gueniffey, Patrice. (1993). Le nombre et la raison. La Révolution française et les élections. Paris : Édition de l'EHESS.

(2001). La revolución Francesa y las elecciones. Democracia y representación a fines del siglo XVIII. México: IFE, FCE.

Guerra, François- Xavier. (1993). "La metamorfosis de la representación en el siglo XIX". En: Couffingal George, Democracias posibles. El desafío latinoamericano, (Comp.). Argentina: FCE, pp. 39-67.

. (1999). "El soberano y su reino. Reflexiones sobre la génesis del ciudadano en América Latina". En: Sábato, Hilda (Coord.) Ciudadanía política y formación de las naciones. Perspectivas históricas de América Latina. México: FCE, pp. 33-61.

Helg, Aline. (2004). Liberty \& Equality in Caribbean Colombiano.1770-1835. Chapel Hill- Londres: The University of north Carolina Press.

Herzog, Tamar. (2000). "La vecindad: entre condición formal y negociación continua. Reflexiones en torno a las categorías sociales y las redes personales". En Anuario del IEHS. Buenos Aires: 15, pp. 123-131.

Irurozqui Marta. (2000). A bala, piedra y palo. La construcción de la ciudadanía política en Bolivia, 1826-1952. Sevilla: Diputación de Sevilla.

(2005). "De cómo el vecino hizo al ciudadano en Charcas y de cómo el ciudadano conservó al vecino en Bolivia, 1809-1830". En: Rodríguez Jaime (coord.), Revolución, Independencia y las nuevas Naciones de América. Madrid: Mapfre Tavera, p. 614 - pp. 451-484.

Kuethe, Allan. (1993). Reforma militar y sociedad en la nueva granada 17731808. Bogotá: Banco de la República. 
López, José Hilario. (1833). Secretario de Estado en el despacho de Guerra y marina. Exposición que hace al congreso de la Nueva Granada en 1831 sobre los negocios a su cargo. Bogotá.

Malamud, Carlos. (1997). partidos políticos y elecciones en la Argentina: La liga del sur (1908-116). Madrid: UNED.

Manin, Bernard. (1998). Los principios del gobierno representativo. Madrid: Alianza editorial.

Marchena Fernández, Juan. (1982). La institución militar en Cartagena de Indias 1700-1810. Sevilla: Escuela de Estudios Hispanoamericanos.

McEvoy, Carmen. (1997). La utopía republicana. Ideales y realidades en la formación de la cultura política peruana (1871-1919). Lima.

Múnera, Alfonso. (1998). El fracaso de la Nación. Región, clase y raza en el Caribe colombiano (1717-1810). Bogotá: Banco de la República/ El Áncora editores.

Murilo de Carvalho, José. (1995). Desenvolvimiento de la ciudadanía en Brasil. México: FCE.

Obando, Antonio. (1835). Exposición presentada al Congreso de la Nueva Granada por el secretario de Guerra y Marina, 1 de marzo. BNC, Quijano, $27,2$.

O'Gorman, Frank. (1989). Voters, patrons and parties: the unreformed electorate of Hanoverian England, 1734-1832. Oxford: Clarendon Press.

(1992). "campaign, rituals and ceremonies: the social meaning of elections in England, 1780-1860". En: Past \& Present. 135, 79115.

Peloso Vincent. (1996). "Liberals, Electoral Reform, and the Popular Vote in Mid-nineteenth century Peru". En: Peloso, Vincent \& Tenenbaum, Barbara (eds.), Liberals, Politics, and Power: State Formation in Nineteenth.Century Latin America. Athens.

Pinzón de Lewin, Patricia. (1994). El ejército y las elecciones. Ensayo Histórico. CEREC.

Posada Carbó, Eduardo. (2000). "Malabarismos electorales. Una historia comparativa de la corrupción del sufragio en América latina, 1830-1930". En: ortiz, L. y Uribe urán, V. (eds.), Naciones, gentes y territorio. Ensayos de historia e historiografía de América latina y el Caribe. Medellín: Editorial Universidad de Antioquía, pp. 270-304.

Posada Carbó, Eduardo (ed.). (1996). Elections Before Democracy. The History of Elections in Europe and Latin America. Houndmills and London. 
Puentes, Milton. (1961). Historia del Partido Liberal Colombiano. Bogotá.

Quijada, Mónica. (1994). “QQué nación? dinámicas y dicotomías de la nación en el imaginario hispanoamericano del siglo XIX". En Cuadernos Ahila, imaginar la nación No 2, http://www.ahila.nl/publicaciones/cuadernos.html;

Restrepo Lince, Pastor. (1993). Genealogías de Cartagena de Indias. Bogotá: Instituto Colombiano de Cultura Hispánica.

Romanelli, Raffaele (dir.). (1998). How did they become voters? The history of franchise in modern European representation. La Haye: Kluwer Law International.

Romero, Aguirre. (1947). Alfonso, Ayer, hoy y mañana del liberalismo colombiano. Bogotá: Editorial lqueima.

Rosanvallon, Pierre. (1992). Le sacre du citoyen. Histoire du suffrage universel en France. Paris : Gallimard.

Sábato, Hilda \& Elías, Palti. (1990). “¿Quién votaba en Buenos Aires? Práctica y teoría del sufragio, 1850-1880". En: Desarrollo Económico, No.119 (oct.dic.).

Sábato, Hilda. (1992). "Citizenship, Political Participation and the Formation of the Public Sphere in Buenos Aires, 1850s-1880s.". En Past and Present, 136.

(2003). La vida política en la Argentina del siglo XIX. Armas, votos y voces. Buenos Aires: FCE.

Saether, Steinar. (2005). Identidades e independencia en Santa Marta y Riohacha, 1750-1850. Bogotá: ICANH.

Samper, José María. (1984). Ensayo sobre las revoluciones políticas. Bogotá: Incunables (primera edición, 1861).

Sartori, Giovanni. (1994). Partidos y sistemas de partidos. Madrid. Alianza Editorial.

Sourdis, Adelaida. (1988). Cartagena de Indias durante la primera República, 1810-1815. Bogotá: Banco de la República.

Uribe Urán, Víctor. (2008). Vidas honorables. Abogados, familia y política en Colombia 1780-1850. Medellín: Fondo editorial EAFIT, Banco de la República.

Uribe Vargas, Diego. (1985). Las Constituciones de Colombia. Madrid: Editorial Cultura Hispánica. 
Valenzuela, Samuel. (1985), Democratización vía reforma: la expansión del sufragio en Chile. Buenos Aires: Ediciones IDES.

Recibido: Noviembre 22 de 2011

Aprobado: Mayo 7 de 2012 